\title{
Troubled Waters: Tracing Globalization and Waste in the Delaware River
}

\author{
Craig Borowiak, Haverford College \\ Vicky Funari, Haverford College \\ jesikah maria ross, Capital Public Radio \\ Helen K. White, Haverford College
}

ABSTRACT In spring 2014, an interdisciplinary media project titled "Troubled Waters: Tracing Waste in the Delaware River" was organized at Haverford College. This project brought together more than 50 students from four courses comprising introductory political science, chemistry, and documentary film students, as well as a community media artist and community partners. The aim was to explore the causes, impacts, and meanings of different types of waste that are polluting the Delaware River. Chemistry students collected samples to determine the presence of chemicals from various waste products, political science students traced the waste to globalized production processes, and documentary students explored diverse ways of representing the theme of waste on screen. This article describes the project and how it might serve as a pedagogical model for multicourse interdisciplinary collaboration and community engagement.

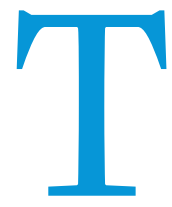

eaching undergraduates about globalization is often a matter of debunking myths, uncovering hidden system logics, and encouraging students to think geographically about connections between local practices and global processes. One proven way to do this is to have them research and map the global production processes that bring everyday items such as t-shirts and water bottles into their closet or refrigerator (Barndt 2008; Rivoli 2009; Sparke 2013). These assignments are useful for teaching students about the geographies of globalization and about trade and transnational production. They also make students aware of how daily decisions about what they eat, wear, and use connect them with workers in otherwise distant parts of the world. In this way, they foster sensitivity to issues of global citizenship and transnational justice that stem from these connections (Young 2011).

Such mapping projects, however, tend to focus only on production and consumption, leaving unstudied the role of waste in the life cycle of commodities. Waste flows are as much a facet of globalization as the laboring aspects of global commodity

Craig Borowiak is associate professor in political science at Haverford College. He can be reached at cborowia@haverford.edu.

Vicky Funari is a documentary filmmaker and an artist-in-residence at Haverford College. She can be reached at vfunari@sonic.net.

jesikah maria ross is an interdisciplinary artist and the Senior Community Engagement Strategist at Capital Public Radio. She can be reached at jmr@praxisprojects.net.

Helen K. White is associate professor in chemistry at Haverford College. She can be reached at hwhite@haverford.edu. chains, and they are equally implicated in local and trans-local justice dynamics (Clapp 2002); however, too often, they drop out of the picture. There are practical reasons for this. Whereas the production process draws diffuse components together into commodities, the waste process breaks commodities apart into diffuse material fragments and anonymous chemical flows. Consequently, individual waste items can be surprisingly difficult to trace without a digital tracer or label-tracking mechanism (Lepawsky 2014; Milmo 2009). Given such complexities, how might a globalization mapping project be adapted to take waste into account? How might the waste stream and its social and political repercussions be studied and represented? Could this be done in a way that fosters civic engagement with local communities?

These are the types of questions we tackled at Haverford College in spring 2014 in an interdisciplinary media project titled "Troubled Waters: Tracing Waste in the Delaware River." This project brought together a political scientist, a chemist, a documentary filmmaker, a community media artist, and community partners, as well as more than 50 Bryn Mawr and Haverford students from four courses across three divisions. The aim was to explore the causes and impacts of different types of waste present in the Delaware River.

The idea for the project originated when Vicky Funari, visiting filmmaker at Haverford College's Hurford Center for the Arts and Humanities, proposed media artist jesikah maria ross for a Mellon Creative Residency. ${ }^{1}$ The two started seeking ways to use ross's socially engaged art expertise to build connections among 
disciplines and with local communities. After soliciting initial interest, Funari and ross convened a meeting with professors Craig Borowiak (political science) and Helen White (chemistry and environmental studies) to brainstorm possibilities. From the beginning, the intention was not to design a new course but rather to fashion a collaborative project around existing course structures. The idea emerged of doing a joint mapping, research, and documentary project that would begin not with a consumer item but instead with chemical waste compounds found in the Delaware River. For ross, whose work explores collaborative placebased storytelling, the river offered a promising way to connect with local environmentalists and to bridge the divide between the classroom and the larger community. For Borowiak, the project provided a waste-centered corrective to the mapping-globalproduction assignment he used in his introductory course. The project also resonated with White's teaching and research, which centers on chemical contaminants found in aquatic systems. Funari wanted to introduce documentary film students to collaborative, multiplatform production models and to invite them to explore interdisciplinary documentary practice. For documentary students, the themes of waste, river, and research were rich with potential images, sounds, metaphors, and storylines to discover. For everyone, the project offered a way to teach students core disciplinary research skills while also modeling both the value and the challenges of interdisciplinarity for addressing complex, socially meaningful problems. our experiences as contributions to the burgeoning conversation on effective ways to make interdisciplinary environmental pedagogy succeed.

\section{CHEMISTRY}

The chemistry component of this project was conducted by junior natural science students in White's "Superlab" course, a standalone, half-semester laboratory class created to give students experience designing experiments that answer novel research questions. Beginning in February, White's students made several trips into the field to collect water and sediment samples from the Delaware River and its tributaries. Students and faculty from the other courses were invited to join the field trips. The students brought their samples back to the chemistry lab to analyze for the presence of waste-related chemicals. White had collected similar samples before the course began and was able to guide students in their search. Working in groups of two or three, the students analyzed seven categories of waste chemicals: flame retardants, petroleum, pharmaceuticals, hormones, pesticides and herbicides, plasticizers, and human waste. From within these categories, students were responsible for selecting a specific chemical (e.g., glyphosate or estrogen) on which to focus their analysis. They analyzed its chemical composition; tested for its presence and quantities in the river samples; and prepared data visualizations with chemical diagrams and descriptions of the chemical's properties, its importance,

\section{For everyone, the project offered a way to teach students core disciplinary research skills while also modeling both the value and the challenges of interdisciplinarity for addressing complex, socially meaningful problems.}

The project involved chemistry students collecting and analyzing samples from the Delaware River to identify waste chemicals, their chemical origins, and their potential health implications. Political science students traced the chemicals to particular products and companies and to patterns of production, consumption, and regulation, which they mapped using digital software. Finally, documentary film students explored diverse ways of representing the theme of waste on screen, using field trips and research of the other classes to learn about their topics and to collect images, sounds, and information. All of this was accomplished in partnership with the Delaware Riverkeeper Network, a civil-society network that champions the rights of communities to a freeflowing, clean, and healthy river and tributaries. Although students carried out their primary research within the context of their own course, we created cross-class collaborations through periodic interclass meetings and shared digital platforms. The project culminated in a final public event at which students presented their work via a website that ross created to archive and establish a digital public presence for the project. Throughout, ross served as the lead artist and project facilitator.

This article describes the project components and highlights the benefits and challenges of our pedagogical experiment. As we discovered, interdisciplinary research and civic engagement open up new and more holistic perspectives on waste, but such approaches also put pressure on institutional constraints-requiring more time from faculty, students, and residents alike. We offer possible sources for its presence and current quantities in the river, and what might be done to reduce levels.

\section{POLITICAL SCIENCE}

The political science component of the project was undertaken by entry-level students in Borowiak's "Politics of Globalization" course. Like the chemistry students, the political science students were divided into small groups and asked to choose a specific chemical from within the seven categories of waste, although they did not always choose the same chemical as the chemistry students. The researched chemicals included codeine, phthalates (a plasticizer), crude oil, estrogen, polybrominated diphenyl ethers (PBDE, a type of flame retardant), glyphosate (an herbicide), and caffeine. They were required to trace their selected chemical to particular commodities and to the companies that produce them. They then mapped the supply chains for those commodities, giving particular attention to trans-local patterns in the production processes and to the underlying labor, environmental, and regulatory conditions. Based on their research, they were tasked with building interactive digital maps that integrated images and narrative to illuminate their findings.

\section{DOCUMENTARY FILM}

The documentary component of the course was carried out by students from two of Funari's documentary film courses: an introductory course titled "Documentary Film and Approaches to Truth" 
and a more advanced course titled "Topics in Video Production: The Documentary Body." Students in these courses created short films on themes related to the Delaware River, waste, and research being conducted by students in the other courses. Students exercised considerable latitude in what footage they generated and how they structured their films. Many chose to accompany the chemistry students into the field as well as into the laboratory space. Working either in groups or alone, students completed seven films in total, each five to ten minutes long.

\section{CIVIC ENGAGEMENT}

We wanted to tie this project to the work of community practitioners working on the river. Such partnerships were seen as a way to improve the research and amplify its impact while also fostering
Neatline is designed for users to tell stories using maps and timelines. Library staff helped set up the software and provided in-class training and case-by-case technical support for students. Technical support also is an inherent part of video making in the academic context. In addition to the usual support from laboratory staff in learning camera, sound, and editing skills, this assignment required extra staff and equipment support to enable documentary students to share footage.

\section{FACILITATION}

"Troubled Waters" involved a complex set of collaborations that required extensive communication among the coordinating faculty and project participants. Here, ross's role as the project orchestrator was crucial. She accompanied students on field trips,

\section{“Troubled Waters" involved a complex set of collaborations that required extensive communication among the coordinating faculty and project participants.}

civic awareness and bridging the divide separating the college from its social and environmental surroundings. ross brought her experience with community-engaged media projects to bear and was able to establish a partnership with the Delaware Riverkeeper Network. Maya van Rossum, the Delaware Riverkeeper, met with our students in the field, through interviews, and in our classrooms to discuss waste and the river.

\section{CROSS-CLASS COLLABORATION}

As project organizers, we worked well together and made a point of accommodating one another's pedagogical needs. We were in regular communication before, during, and after the semester. To facilitate collaboration among the classes, we organized a series of three cross-class meet-ups in which students and faculty from the participating courses gathered together and learned from one another. The first meet-up, held near the beginning of the semester, introduced the project and engaged students in team-building activities. The second meet-up, held mid-semester, involved a presentation and conversation with Maya van Rossum. The third meet-up, held near the end of the project, gave students an opportunity to present and workshop their works-in-progress across disciplines. In addition to these meet-ups, we shared contact information and established a digital repository for students to share documents, images, and videos across classes.

\section{RESEARCH SUPPORT}

For many of the introductory students, this project was their first time conducting original college-level research. Most had, at best, limited experience accessing the college library's wide spectrum of resources and even less experience working with Haverford's research librarians. To help the students with their research, the college's science, social science, and digital scholarship librarians customized resource-guide websites specifically for this assignment. They also made themselves available throughout the semester.

Technical support was crucial for this project. The digitalmapping platforms were created using software called Neatline, which is a plug-in for Omeka, an open-source archive software. visited each of the courses, coordinated with librarians, consulted with students from each group, established and maintained contact with the Delaware Riverkeeper, and emceed the cross-class meet-ups and final presentation sessions. It would have been difficult to accomplish such an ambitious project without a point person to keep the communication flowing. ross did this in her role as an artist-in-residence-despite being on campus for only three separate two-week visits.

\section{PRESENTATIONS}

The project culminated in "Pollution, Politics \& Place," a grand four-hour public event offering multiple opportunities for students and audiences to interact around the project research and creative work. The first part of this event resembled a science fair, in which audience members moved around seven Pollution Exploration Stations, choosing which to visit and how long they wanted to engage with the presenters. At each station, chemistry and political science students stood together in front of posters and computers preloaded with their digital maps and data visualizations. (The stations were designed and installed by ross.) Rather than giving long presentations, students came prepared to field a wide variety of questions from audience members. Each working group of chemistry and political students was divided in half, with one half presenting their work while the others visited other stations. Thus, the audience consisted of students, the wider college community, and the general public. The presentations were followed by a catered dinner at which participants discussed project ideas and experiences. After dinner, there was a screening and discussion of the documentary students' finished films.

\section{FINAL PRODUCT AND FINDINGS}

To interlink the research and creative work, ross created an interactive website and protocols so that students could post their work to a platform accessible to both campus and community stakeholders. After students posted their work, she curated the posts so that the site conveys and unites diverse disciplinary perspectives on waste in the Delaware River. The site includes the documentary films, the political science digital maps and narratives, and the chemistry data visualizations, as well as photographs of 
research in progress and contextual information. The website is http://troubledwaters2014.tumblr.com. ${ }^{2}$ The Tumblr site made the project cohesive by creating a single space in which the larger group effort was made visible and accessible.

What did the students find? Students studying glyphosate (i.e., a key ingredient in Monsanto's "Round-up" product line) traced Monsanto's global influence and the social and political controversies surrounding the company. They also examined possible health risks of glyphosate and how runoff from local golf courses and farms (which they geolocated) makes its way into the river. Students working on phthalates, which are mainly used to increase the flexibility of plastic, drew connections among phthalates in the river, Dow Chemical's production of polyethylene terephthalate (PET; a plastic), and Nestle's production of plastic water bottles. They located many of Nestle's international headquarters and bottling facilities and identified regulations and the chemical's environmental animal- and human-health effects. Other students used the prospect of finding pharmaceuticals in the river as a basis to examine the Swiss drug company Siegfried International, LTD, which has its US headquarters near the Delaware River. Another group focused on the oil industry and the impacts of a 2014 oil spill in the river. They learned how to assess the size and impacts of oil spills, and they drew connections to the emergent shale-oil industry and the larger global petroleum market. It is interesting that the chemistry students found a greater presence of petroleum-based sealants (i.e., designed to cover parking lots and suburban blacktops) than crude oil. The group working on hormones explored the presence of estrogen in the river and speculated about how it might be related to a birth-control-pill producer such as Actavis. They examined Actavis's global market share and different countries' efforts to regulate endocrine disrupters. They also learned about the difficulty in cleaning waters of hormone waste and tracing this waste to particular commodity producers. The student group working on human waste in the river focused on caffeine and how project as part of an introductory course. Most were shocked to discover how much work a documentary that engages with ongoing, unfinished research from the social and natural sciences entails. Some expressed frustration at how little solid information they had and at how much raw information they were being asked to comprehend. However, they met the challenge with creativity and elegance. Some adopted a conventional documentary approach, with narration and interviews. Others made extensive use of humor, producing mockumentaries and spoofs. Still others worked in a more abstract register, using images from the chemistry students' sampling and analysis to create poetic meditations on water and the labor of scientific research.

\section{PEDAGOGICAL ASSESSMENT AND LESSONS LEARNED}

In debriefing on the project, faculty and artists noted that we had each accomplished our pedagogical goals. In course evaluations, students from each class commented on how much more they learned about waste, rivers, global production, and the community as a result of the collaboration. They also reported the benefits of having to communicate their disciplinary knowledge to students from other disciplines in a multidisciplinary effort to address real-world problems.

For the introductory political science course, the project put entry-level students in the position of a researcher doing original work and provided learning skills that will prove useful later in their education. It also gave them experience with new digital technologies, spatial and geographic reasoning, oral and visual communication of findings in public, and different forms of collaboration across disciplines and with community partners. More substantively, it gave them new multidimensional insights into the global and local dimensions of production, consumption, and waste and their connections to Delaware River communities. Many realized how understanding the chemical compounds that comprise our modern life matters for policy making and for local, national, and global well-being.

\section{It also gave them experience with new digital technologies, spatial and geographic reasoning, oral and visual communication of findings in public, and different forms of collaboration across disciplines and with community partners.}

it might be sourced to a coffee producer such as Dunkin' Donuts. They used the connection to coffee to explore the global coffee market and the politics of fair-trade versus conventional coffee. Finally, a group working on flame retardants focused on PBDE flame retardants and how they had been used extensively in the United States in everything from clothing to mattresses before Environmental Protection Agency (EPA) regulations called for them to be phased out by 2009. The students used the presence of PBDEs to study the proximity of dumps to the river and to study the use of flame retardants in Serta mattresses. They traced the geography of Serta-mattress production, the global presence of ICL Industrial Products, Inc. (i.e., a PBDE producer), and efforts to regulate and phase out PBDEs internationally.

For documentary students, this project mirrored the realworld process of filmmaking more closely than a traditional production class. The introductory documentary students struggled with the scope and timing of working on such an involved
In a typical production class, the documentary students would have learned basic production skills and studied documentary theory and history. This interdisciplinary project gave them added challenges: exploring topics unfamiliar to them, getting off campus and into physical contact with the surrounding region, engaging with students in other disciplines and observing their methodologies, and being aware of and responsible to these other forms of knowledge production. Although the resulting films were no more or less technically skilled than in any other semester, they had a thematic and conceptual richness that was a direct result of the project's structure and ambition.

For the chemistry students, the project enabled them to apply their prior knowledge to explore the fate of human-derived chemical compounds that are commonly released into the environment. The chemistry students were able to display their disciplinary knowledge, but they also had to learn how to communicate this 
information in lay terms to the political science and documentary film students. For the majority of chemistry students, this was their first foray into the importance of science communication, and they learned how to present their findings in a way that connected the general public to the nature of scientific research. The chemistry students learned more about the social function of a chemist than interdisciplinary research, although several commented that the work of the political science students enabled them to see the broader effects of the chemical compounds that they studied.

Not everything went smoothly in this project. In light of student feedback and some of the difficulties faced, we offer the following lessons learned for any similar project:

(1) Let students opt in. We created this dynamic and innovative learning experience for our students, but all did not choose to be involved. Rather, it was part of their required class work. Consequently, some students expressed a sense of being forced to engage in this project and others complained about the reduced lecture time and lack of ability to focus on their chosen discipline. If possible, create ways for students to self-select into the project to ensure that participants want to be there and do this type of work.

(2) Choose the right platforms. Technology made this project possible but it also imposed significant constraints. The Neatline software, for example, proved to be more cumbersome and difficult to learn than expected. The Moodle site designed to share material across courses worked well for ordinary documents but proved cumbersome for sharing images, especially video.

(3) Timing is important. The sequencing of our students' research presented challenges for students who depended on the findings of others. Ideally, chemistry students would have already identified chemicals in the river in sufficient quantities before the political science students embarked on their research; as it happened, this was not the case. Political science students chose their chemicals based largely on White's prior experience rather than on the actual quantities discovered by chemistry students. The sequencing of research also posed challenges for documentary students. Due to the long timeline for making even a short film, they had to begin their films before the chemistry and the political science students had finished much of their research, so they could not effectively build the whole research into their film projects. Some opted to document the chemistryresearch process rather than the results, whereas others relied on preexisting information to complete their films. Some of these problems might have been avoided had we organized this project with subsequent courses spread over two semesters rather than concurrent courses in one semester. Doing so, however, would have lessened the esprit du corps and it would have required more serious confrontation with established departmental practice (e.g., the Chemistry Superlab course taught by White is coordinated with departmental colleagues and is intended for the spring semester). This raises a fourth lesson.

(4) Interdisciplinary research across courses is different from other types of interdisciplinary pedagogy. Because this collaboration took place across different rather than in a single course, the faculty had greater autonomy in the design and teaching of individual content. This avoided the sort of tensions (latent or manifest) that can develop among instructors in a co-teaching environment. However, other tensions emerged. For example, some chemistry students resisted having their research "exploited" by documentary students. Faculty labored to explain to all sides that these dynamics are a common part of any collaborative effort, especially when media representations are being created. Additionally, balancing the aims of the project with other curricular objectives and departmental expectations was challenging at times. For instance, the chemistry course was geared toward more advanced science majors, whereas the political science students were primarily first- and second-year students. This generated imbalance in the interactions-an imbalance that was compounded by the political science students' reliance on the chemistry students' scientific research.

(5) Original interdisciplinary research is time-consuming. We asked much of our students and ourselves in this project. We were generally thoroughly impressed by both the quality and sheer quantity of work accomplished. Nevertheless, it was taxing on students, several of whom reported that the project took too much time: working in disciplinary teams, going on field trips, meeting up with other classes, and doing research or media production. It is important to be realistic with students at the beginning of the semester about how much work and time it will take.

\section{CONCLUDING REMARKS}

This project was successful due to the dedication and hard work not only of diverse faculty and artists but also of support staff and community partners. As a model for studying waste, however, it need not entail so many actors and such ambitious and complex forms of collaboration. It could be replicated on a smaller scale in the context of single courses. A mapping-waste assignment, for example, might begin not with the research from a concurrent chemistry course but instead from a prior semester's course, an EPA report, a professional study from a Riverkeeper Network, or any known category of waste. Moreover, the mapping and representation of the findings could be accomplished easily using simpler technology, such as Google maps and posters. Conversely, such projects also could be more successful if scaled up, with more course time allotted, closer coordination of schedules among participating courses, and more tailoring around the five lessons learned delineated previously.

\section{NOTES}

1. Supported by the Andrew W. Mellon Foundation, the Mellon Creative Residencies encourage Bryn Mawr, Haverford, and Swarthmore faculty to design arts residencies that combine pedagogy, public presentation, and informal exchange among artists, faculty, students, the wider campus, and area communities.

2. The current version of the website also includes new material added from further documentary research and interviews conducted in fall 2014. A short film about the "Troubled Waters" project as a whole is available at www. youtube.com/watch?v=mLCETJzICFs\&feature=youtu.be.

\section{REFERENCES}

Barndt, Deborah. 2008. Tangled Routes: Women, Work, and Globalization on the Tomato Trail, second edition. Lanham, MD: Rowman \& Littlefield. 
Clapp, Jennifer. 2002. "Distancing of Waste: Overconsumption in a Global Economy." In Confronting Consumption, ed. Thomas Princen, Michael Maniates, and Ken Conca, 155-76. Cambridge, MA: MIT Press.

Lepawsky, Josh. 2014. "The Changing Geography of Global Trade in Electronic Discards: Time to Rethink the E-Waste Problem." The Geographical Journal 181 (2): 147-59.

Milmo, Cahal. 2009. "How a Tagged Television Set Uncovered a Deadly Trade." Independent, February 17. Available at www.independent.co.uk/ news/world/africa/how-a-tagged-television-set-uncovered-a-deadlytrade-1624873.html.

Rivoli, Pietra. 2009. Travels of a T-Shirt in the Global Economy, second edition. Hoboken, NJ: John Wiley \& Sons.

Sparke, Matthew. 2013. Introducing Globalization: Ties, Tension, and Uneven Integration. Walden, MA: Wiley-Blackwell.

Young, Iris Marion. 2011. Global Justice. New York: Oxford University Press. 